\title{
Sorbent based on chitosan and polyurethane foam for cleaning aqueous media from metal ions and dyes
}

\author{
(C) Quyen Thi Quynh Anh, Lyubov A. Zenitova, ${ }^{*+}$ and Ngo Hong Nghia \\ Department of Synthetic Rubber. Kazan National Research Technological University. \\ K. Marx St., 68. Kazan, 420015. Republic of Tatarstan. Russia.E-mail: zenit@kstu.ru
}

\begin{abstract}
*Supervising author; ${ }^{+}$Corresponding author
Keywords: sorbent, polyurethane foam, chitosan, oil, metal ions, dye.
\end{abstract}

\begin{abstract}
This article touches upon an urgent subject at present - the development of a sorbent for purifying water resources from metal ions and dyes. For these purposes, a sorbent based on polyurethane foam filled with $30 \%$ chitosan was developed to eliminate oil spills. It is well known that chitosan is an effective absorber of metal ions, it is recommended to use chitosan for metal ions extraction from waste waters of galvanic, mining, processing and textile industries. In this purpose, it is important to research which extent of the sorbent be developed, for oil spills treatment, and have metal ions absorbability. Unfilled polyurethane foam has been studied to use as a sorbent for metal ions previously, this research shown that they are not suitable sorbents for these purposes. In order to develop a versatile sorbent, a study to combine the ability to absorb oil and oil products of polyurethane foam and the ability to purify water from metal ions and dyes of chitosan has been carried out.

The best degree of purification by the sorbent is observed at a concentration of $\mathrm{Cu}^{2+}$ ions of $100 \mathrm{mg} / \mathrm{l}$ and $\mathrm{Pb}^{2+}$ ions of $200 \mathrm{mg} / \mathrm{l}$. In addition, the sorbent is proved to be effective to a dyes of $500 \mathrm{mg} / \mathrm{g}$ concentration for their removal from aqueous solutions.

Sorption isotherms according to the Langmuir and Freundlich models have high confidence coefficients -

$\mathrm{R}^{2}>0.87$. Equilibrium parameters $\left(\mathrm{R}_{\mathrm{L}}\right)$ for Langmuir isotherms are in the range of $0<\mathrm{R}_{\mathrm{L}}<1$. The process of sorbents adsorption for both $\mathrm{Cu}^{2+}, \mathrm{Pb}^{2+}$ ions and dyes is satisfactorily described by both the Langmuir and Freundlich isotherms.

Low values of $\mathrm{E}$ and $\mathrm{G}$ indicate the occurrence of predominantly physical adsorption in all the cases studied.

It has been established that the developed sorbent, which is a specific sorbent for cleaning water surfaces from oil pollution, also allows to purify wastewater of chemical enterprises containing metal ions $\mathrm{Cu}^{2+}$ and $\mathrm{Pb}^{2+}$ up to $29 \%$ and dyes in wastewater of textile industries up to $97 \%$, which proves its versatility.
\end{abstract}

\section{References}

[1] M.A. Ivanova, L.A. Zenitova. Sorbent for oil spills treatment on the basis of polyurethane foam and foam polystyrene waste. Ecology and Industry of Russia. 2015. No.4. P.42-46. (russian)

[2] B.T. Tran. Chitosan: precious raw materials from seafood processing. https://tranbathoaimdphd.wordpress.com/2018/03/19/chitosan-nguyen-lieu-quy-tu-phe-pham-che-bienthuy-hai-san/

[3] M. Kaya, T. Baran, S. Erdoğan, A. Menteş, M.A. Özüsağlam, Y.S. Çakmak. Physicochemical comparison of chitin and chitosan obtained from larvae and adult Colorado potato beetle (Leptinotarsa decemlineata). Mater. Sci. Eng. 2014. Vol.45. P.72-81.

[4] M. Kaya, Y.S. Çakmak, T. Baran, M.A. Özüsağlam, A. Menteş, K.O. Tozak. New chitin, chitosan, and O-carboxymethyl chitosan sources from resting eggs of Daphnia longispina (Crustacea); with physicochemical characterization, and antimicrobial and antioxidant activities. Biotechnol. Bioprocess Eng. 2014. Vol.19. P.58-69.

[5] M.R. Kumar, R.A. Muzzarelli, C. Muzzarelli, H. Sashiwa, A. Domb. Chitosan chemistry and pharmaceutical perspectives. Chem. Rev. 2005. Vol.104. No.12. P.17-84. (russian)

[6] E.A. Taranovskaya, N.A. Sobgayda, I.P. Alferov and P.A. Morev. Wastewater treatment using chitosan. Bulletin of Orenburg State University. 2015. Vol.85. No.10. P.322-326. (russian)

[7] E.A. Taranovskaya, N.A. Sobgayda and D.V. Markina. Production technology and use of granular sorbents based on chitosan. Chemical and Oil \& Gas Engineering. 2016. No.5. P.42-45. 
[8] Quyen Thi Quynh Anh, L.A. Zenitova, M.A. Ivanova. polymer composition based on polyurethane foam and chitosan. Bulletin of the Technological University. 2017. Vol.20. No.11. P.32-35. (russian)

[9] A. Gamal. Removal of Some Heavy Metal Ions Using Grafted Polyurethane Foam. Polymer-Plastics Technology and Engineering. 2008. Vol.47. P.106-113.

[10] Quyen Thi Quynh Anh, D.I. Fazylova, A.A. Nazirova, L.A. Zenitova. Polyurethane foam filled with chitosan - a sorbent for the elimination of oil pollution. Ecology and Industry of Russia. 2018. Vol.23. No.5. P.37-41. (russian)

[11] Quyen Thi Quynh Anh, L.A. Zenhitova. Liquidation of oil spills using a sorbent based onchitosan. IOP Conference Series Earth and Environmental Science. St. Petersburg Polytechnic University. 2019. No.337. P.1-6. (russian)

[12] D.V. Kozlov, G.A. Kostin, A.P. Chupakhin. Basic principles of spectroscopy and its application in chemistry. Novosibirsk: [s. n.]. 2008. 121p. (russian)

[13] P.3. Galimova, I.G. Shaikhiev, S.V. Sverguzova. Calculate the results of adsorption processes study using the software microsoft excel. Workshop. Kazan-Belgorod. 2017. 60p. (russian)

[14] Angel Ramon Hernández-Martínez, Gustavo A. Molina, Luis Fernando Jiménez-Hernández, Adrian Hendrik Oskam, Gerardo Fonseca. Evaluation of Inulin Replacing Chitosan in a Polyurethane/Polysaccharide Material for $\mathrm{Pb}^{2+}$ Removal. Molecules. 2017. Vol.22. No.12. P.1-15.

[15] Lee cheon ho, Young Gyu Jeong, EL. Preparation and acid dye adsorption behavior of polyurethane/chitosan composite foams. Fibers and Polymers. 2009. Vol.10. No.5. P.636-642. 